\title{
CT head findings in suspected cases of head injury
}

\author{
Surendra Maharjan', Saroj Chhetry ${ }^{2}$, Neyaj Ahmed ${ }^{3}$, Pasang Sherpa ${ }^{4}$ \\ ${ }^{1}$ Assistant Professor, Department of Radio-diagnosis \& Medical Imaging, Universal College of Medical Sciences, \\ Teaching Hospital, Bhairahawa, ${ }^{2}$ Radiographer, Department of Radiology \& Imaging, Sahid Gangalal National Heart \\ Center, Kathmandu, Nepal, ${ }^{3}$ Radiologic Technologist, Global Hawk Imaging \& Diagnostics LLC, Dubai, United Arab \\ Emirates, ${ }^{4}$ Senior Radiologic Technologist, Department of Radiology and Imaging, National Institute of Neurologica \& \\ Allied Sciences, Kathmandu, Nepal
}

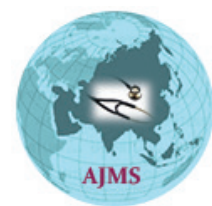

A B S T R A C T

Background: Head injury is one of the leading causes of morbidity and mortality throughout the world. Fall injury is the main cause of head trauma followed by road traffic accidents (RTA) and physical assault. Every victim with altered level of consciousness must be evaluated for brain injury. Radiological evaluation has undergone dramatic changes with the advent of computed tomography (CT) as it can precisely define the nature and location of the culprit lesion(s). Aims and Objective: To identify the major CT scan findings in suspected cases of Head injury. Materials and Methods: Three hundred seventeen patients of age 4 years and above, with suspected cases of head injury attending emergency department of TUTH during a period of 3 months (28 June 2012 to 28 September 2012) were included in this study. Non-contrast CT scan of head was performed in a single slice Hitachi Spiral CT scanner and $10 \mathrm{~mm}$ axial slices of head without any interslice gap were obtained at 15-20 degrees to the canthomeatal line. Data analysis was performed in SPSS v.21.0 software. Results: From 317 patients studied $198(62.5 \%)$ were male and $119(37.5 \%)$ were female. Head injury was more common in male. 80(25.23\%) were below 15 years of age, 221(69.73\%) were between 16 to 65 years and only $16(5.04 \%)$ were above 66 years of age. The mean age was 28.57 years. In $239(75.4 \%)$ of patients the CT scan was normal. The most common cause of head injury was fall which was found in $210(66.2 \%)$ patients followed by RTA 82(25.9\%) and Physical Assault 25(7.9\%). Fall as a cause of head injury was more common in children and old people, with the RTA being more common in adults and adolescents. The most common positive finding in CT was contusion which was found in $32(10.1 \%)$, $25(7.9 \%)$ had SDH, $11(3.5 \%)$ of the patients had EDH, 10(3.2\%) had SAH. Headache was found to be nonspecific for predicting positive CT findings. Conclusion: CT was found highly sensitive in demonstrating fractures and was considered the modality of choice when imaging suspected cases of head injury and in emergency patients due to its accuracy, reliability, safety and wide availability.

Key words: Glasgow coma scale (GCS), Head injury, Computed tomography
http://nepjol.info/index.php/AJMS DOI: 10.3126/ajms.v8i2.16205 E-ISSN: 2091-0576 P-ISSN: 2467-9100

\section{INTRODUCTION}

Head injury refers to trauma of the head. This may or may not include injury to the brain. ${ }^{1}$ However, the terms traumatic brain injury and head injury are often used interchangeably in medical literature. ${ }^{2}$ Head injury can be defined as any alteration in mental or physical functioning related to a blow to the head. Loss of consciousness do not need to occur. ${ }^{3}$ Head trauma is a very brief event, which occurs in less than 200 milliseconds (ms), and often in less than $20 \mathrm{~ms}^{4}{ }^{4}$ In patients with multiple traumas, head is the most common organ to be involved. ${ }^{5}$

Polytrauma due to road traffic accidents (RTA) is a leading cause of head injury in teenagers and young adults. ${ }^{6}$ Amongst the severely injured patients, majority survives with severe disability and few continue to be in a vegetative state. Increasing age is associated with poorer outcome in 
patients with head injury. ${ }^{7}$ Computed tomography (CT) has become the diagnostic modality of choice for head trauma due to its accuracy, reliability, safety, and wide availability. ${ }^{8}$

Head injury is one of the most common causes of morbidity and mortality in most countries including Nepal. Internationally, in the United States 1.5 million individuals per year have a head injury. ${ }^{3}$ It is estimated that nearly 1.5 to 2 million persons are injured and 1 million succumb to death every year in India. ${ }^{9}$ Head injury remains an important cause of death anddisability in young adults, with over $50 \%$ of patients experiencing unfavourable outcomes. ${ }^{10}$

Head injury data are difficult to compare internationally for various reasons, including inconsistencies and complexities of diagnostic coding and inclusion criteria, transfers to multiple care facilities (i.e. patient admissions may be counted more than once), and regional medical practices. The true data of head injury and its complications is not available in Nepal. An indirect way of estimation this is to look at traffic accident trends. Traffic related deaths in Kathmandu Valley have steadily increased during 19812003; an annual increase was $3.9 \%{ }^{11}$ Head injury cases outside the capital face a big problem i.e. they are either referred to Kathmandu or treated locally who also face major practical problems of travel time because sometimes the transport time averages more than six hours from any centre outside the capital. ${ }^{12}$ In adults, the leading causes of head injury are RTA and falling down ${ }^{4}$ and in children, fall is the leading cause followed by RTA. Increasing age is associated with poorer outcome in patients with head injury. ${ }^{13}$

The cost to society of head injury is staggering, from both an economic and an emotional standpoint. Almost $100 \%$ of persons with severe head injury and as many as two thirds of those with moderate head injury will be permanently disabled and will not return to their premorbid level of function. ${ }^{14}$ In a study performed by Singh M, Vaishya S, Gupta S and Mehta VS in All India Institute of Medicine, India, it was found that the total expenditure in minor head injury was Rs.7800/patient, in moderate head injury it increased to Rs.22172/patient, whereas in severe head injury, it was found to be Rs.32852 per patient. ${ }^{15}$ This data is also equally applicable in the Nepalese context and shows the economic burden incurred to a country by a case of head injury.

Head injuries are usually associated with structural changes which are better investigated and detected initially by computed tomography of the head. CT scan detects and precisely localizes the intracranial hematomas, brain contusions, edema and foreign bodies. ${ }^{16} \mathrm{With}$ the ubiquitous availability of CT in the 1970s, the diagnosis and management of head trauma have changed significantly. ${ }^{5}$ After its first use in 1978, the usage of skull x-ray, angiography and surgical intervention have been reduced by $24 \%, 84 \%$ and $58 \%$ respectively. ${ }^{17}$

The chaotic traffic in Kathmandu and the current situation of conflict is one of the most common causes of head injury and of emergency room visits. The cost of head injury, both physically as well as economically, is a huge burden for the patient and not only that it is a huge burden for an underdeveloped country like Nepal. Besides the fact that it usually involves the younger age group of population, the most productive of all the age groups towards whom the responsibility of the country lies. This has increased its importance and the need to address it promptly to avoid its feared consequences. So, it has been very important to study the pattern of head injury in our local setting and to correlate the clinical findings with the CT findings.

\section{MATERIALS AND METHODS}

It was a prospective, cross sectional study involving patients presented for CT scan in the Emergency Department from June 2012 to September 2012.The patients with suspected head injury of less than 24 hours, irrespective of modality of injury referred for CT scan were included in the study. Patients of age 3 years and above were taken under the study. Patients with Age less than 4 years; previous history of Stroke or brain tumor; previous history of major CNS operations; history of psychiatric diseases; history of alcohol or drug intake were excluded from the study. A total of 317 patients (198 men and 119 women; age range, 4-84 years; mean age, 28.57years) were identified. The patients with suspected head injury were initially attended by the residential house officers of the department of emergency who evaluated the cares by taking history and doing physical examination. The history especially included cause of injury, use of alcohol or drugs, any past history of psychiatric diseases, stroke and history of vomiting, headache. The patients were also evaluated for the presence of loss of consciousness and external injuries on the scalp. The GCS score was also determined. The GCS score was given using the previous guideline. The patients were then divided into three groups according to the cumulative GCS score: Severe (GCS 8 or less), moderate (GCS 9-12) and mild (GCS 13-15). The patients were then subjected to CT scan of head within 2 hours of evaluation of GCS.

The CT scan was performed with the patient in supine position; head first, from the region of the base of the skull to the vertex. The standard CT scanning technique included 
10-mm slices without interslice gap with a 15-20 degrees angle to the canthomeatal line and parallel to the skull base to reduce the beam hardening artifacts and increase the conspicuousness of the posterior fossa small lesions. The CT was then evaluated in the console room in two window settings: Brain soft tissue for intracranial lesions and bone window for fractures. The CT was evaluated under supervision of a radiologist, the co-guide. The single slice spiral CT scan machine (Hitachi Medical Systems, Japan) was used for scanning purpose. The data thus obtained were compiled and analyzed using standard statistical analysis. SPSS version 21.0 software was utilized for the data analysis and presentation.

\section{RESULTS}

Total 317 patients with suspected head injury underwent CT scan of head.198 (62.5\%) were males and 119(37.5\%) were females. The maximum age was 84 years and the minimum age was 4 years. The mean age was 28.57 years. There were 80 children $(25.23 \%), 221(69.73 \%)$ adults and $16(5.04 \%)$ in age group 66 years and above. The most common cause of head injury was fall $(66.2 \%)$, followed by RTA $(25.9 \%$ ) and assault comprised of remaining $7.9 \%$. Considering the sex of the patients, fall injury was higher in males. RTA as a cause of head injury was also very higher in males (Table 1).

Vomiting, headache, loss of consciousness was the three main symptoms studied in this study. Vomiting was present in $64(20.2 \%)$ of total. Similarly Loss of consciousness was present in 99 (31.2\%). 90 (28.4\%) had headache while $71.6 \%$ didn't have headache.

Most of the patients of head injury had mild GCS score, accounting for $271(85.5 \%)$ of cases, followed by moderate $38(12.0 \%)$ and severe $8(2.5 \%)$ of the total cases (Table 2$)$.

\begin{tabular}{|c|c|c|c|c|}
\hline & \multicolumn{3}{|c|}{ Causes of injury } & \multirow[t]{2}{*}{ Total } \\
\hline & Fall & RTA & Assault & \\
\hline \multicolumn{5}{|l|}{ Gender } \\
\hline Male & 122 & 58 & 18 & 198 \\
\hline Female & 88 & 24 & 7 & 119 \\
\hline Total & 210 & 82 & 25 & 317 \\
\hline
\end{tabular}

\begin{tabular}{lccc}
\multicolumn{3}{l}{ Table 2: Showing glasgow coma scale score } \\
\hline & Frequency & Percent & Cumulative percent \\
\hline Mild & 271 & 85.5 & 85.5 \\
Moderate & 38 & 12.0 & 97.5 \\
Severe & 8 & 2.5 & 100.0 \\
Total & 317 & 100.0 & \\
\hline
\end{tabular}

External injury was present in $206(65 \%)$ and was absent in $111(35 \%)$.

Of total 317 patients, 239 (75.4\%) had normal findings taking external injury as normal. $11(3.5 \%)$ of the patients had EDH, 25(7.9\%) had SDH, $10(3.2 \%)$ had SAH, $32(10.1 \%)$ had contusion (Table 3$)$.

Two hundred seventy-four (86.4\%) cases didn't show fracture while rest 43 showed fracture. Among the fracture cases, linear fracture of the frontal bone was encountered more $12(3.8 \%)$ while depressed fracture of the occipital bone and linear fracture of the temporal bone was least encountered i.e. $2(0.6 \%)$ each (Table 4$)$.

271 cases showed mild GCS and CT findings were positive in only 33 among them. 38 cases showed moderate GCS and CT findings were positive in almost all cases while all 8 patients with severe GCS showed positive CT findings (Table 5).

$15(23.4 \%)$ of patients with vomiting had negative CT findings, whereas $49(76.6 \%)$ of patients with history of vomiting had positive CT findings. 224(88.6\%) of patients without history of vomiting had negative CT findings and $29(11.4 \%)$ of patients without history of vomiting had positive CT findings (Table 6).

\begin{tabular}{|c|c|c|c|}
\hline & Frequency & Percent & $\begin{array}{c}\text { Cumulative } \\
\text { percent }\end{array}$ \\
\hline Normal & 239 & 75.4 & 75.4 \\
\hline $\begin{array}{l}\text { Epidural } \\
\text { hematoma }\end{array}$ & 11 & 3.5 & 78.9 \\
\hline $\begin{array}{l}\text { Sub dural } \\
\text { hematoma }\end{array}$ & 25 & 7.9 & 86.8 \\
\hline $\begin{array}{l}\text { Sub } \\
\text { arachnoid } \\
\text { Hemorrhage }\end{array}$ & 10 & 3.2 & 89.9 \\
\hline Contusion & 32 & 10.1 & 100.0 \\
\hline Total & 317 & 100.0 & \\
\hline
\end{tabular}

\begin{tabular}{lccc}
$\begin{array}{l}\text { Table 4: Distribution showing frequency of } \\
\text { fracture }\end{array}$ & Frequency & Percent & $\begin{array}{c}\text { Cumulative } \\
\text { percent }\end{array}$ \\
\hline Fracture & 12 & 3.8 & 3.8 \\
\hline Linear frontal & 6 & 1.9 & 5.7 \\
Linear parietal & 2 & 0.6 & 6.3 \\
Linear temporal & 5 & 1.6 & 7.9 \\
Linear occipital & 6 & 1.9 & 9.8 \\
Depressed frontal & 4 & 1.3 & 11.0 \\
Depressed parietal & 6 & 1.9 & 12.9 \\
Depressed temporal & 2 & 0.6 & 13.6 \\
Depressed occipital & 274 & 86.4 & 100.0 \\
Absent & 317 & 100.0 & 100.0 \\
Total & & &
\end{tabular}


$72(40 \%)$ of the patients with headache had positive CT head findings. 108(60\%) with headache had normal CT findings. Only 6(4.3\%) patients without headache had positive CT finding while 131(95.7\%) of patients without headache had normal findings in CT (Table 7).

$40(40.4 \%)$ of patients with loss of consciousness (LOC) had negative CT findings while $59(59.6 \%)$ of patients with LOC had positive CT findings. Similarly 199(91.2\%) of patients without LOC had negative CT findings while $19(8.8 \%)$ of patients without LOC had positive CT findings (Table 8).

Chi-square test $(\chi)$ test was determined to find the association of CT findings with causes, headache, vomiting, and fracture cases. The cause of head injury and findings, headache and findings and loss of consciousness and findings are statistically significant at $0.5 \%$ level of significance as calculated values were greater than tabulated values. In other words, they are closely associated with each other.

\section{DISCUSSION}

A total of 317 patients undergoing CT head for suspected head injury $239(75.4 \%)$ had normal findings taking external injury as normal. 11 (3.5\%) of the patients had EDH, $25(7.9 \%)$ had SDH, $10(3.2 \%)$ had SAH, 32 (10.1\%) had contusion. The most common CT finding was contusion. Similarly the study done by Naseri $\mathrm{M}$, et $\mathrm{al}^{18}$, the causes of head injury were as follows: Fall 210 (66.2\%), RTA $82(25.9 \%)$ and Physical Assault 25(7.9\%). Fall was the most common cause of head injury. Similar findings were also present in studies conducted by Alissa $\mathrm{A}^{19}$ in which falling down was most common cause of head injury occupying $71.6 \%$ of all causes and also in studies conducted by Ingebrigsten $\mathrm{T}$ and his fellow workers ${ }^{20}$ and Meerhoff SR and his teammates. ${ }^{21} \mathrm{~A}$ total of 271 cases showed mild

\section{Table 5: Showing GCS score and CT findings}

\begin{tabular}{lcccccc}
\hline & \multicolumn{5}{c}{ Findings } & Total \\
\cline { 2 - 5 } & Normal & Epidural hematoma & Sub dural hematoma & Sub arachnoid hemorrhage & Contusion \\
\hline GCS score & & 3 & 6 & 8 & 16 \\
Mild & 238 & 6 & 14 & 1 & 16 & 371 \\
Moderate & 1 & 2 & 25 & 1 & 0 & 8 \\
Severe & 0 & 11 & & 10 & 32 & 317 \\
Total & 239 & & & & & \\
\hline
\end{tabular}

Table 6: Showing vomiting and CT findings

\begin{tabular}{|c|c|c|c|c|c|c|}
\hline & \multicolumn{5}{|c|}{ Findings } & \multirow[t]{2}{*}{ Total } \\
\hline & Normal & Epidural hematoma & Sub dural hematoma & Sub arachnoid hemorrhage & Contusion & \\
\hline \multicolumn{7}{|l|}{ Vomiting } \\
\hline +ve & 15 & 10 & 18 & 2 & 19 & 64 \\
\hline$-v e$ & 224 & 1 & 7 & 8 & 13 & 253 \\
\hline Total & 239 & 11 & 25 & 10 & 32 & 317 \\
\hline
\end{tabular}

Table 7: Showing headache and CT findings

\begin{tabular}{lcccccc}
\hline & \multicolumn{4}{c}{ Findings } & Total \\
\cline { 2 - 5 } & Normal & Epidural hematoma & Sub dural hematoma & Sub arachnoid hemorrhage & Contusion \\
\hline Headache & & 10 & 23 & 8 & 31 \\
Present & 108 & 1 & 2 & 2 & 180 \\
absent & 131 & 11 & 25 & 10 & 137 \\
Total & 239 & & & & 32 & 317 \\
\hline
\end{tabular}

\section{Table 8: Showing loss of consciousness and CT findings}

\begin{tabular}{|c|c|c|c|c|c|c|}
\hline & \multicolumn{5}{|c|}{ Findings } & \multirow[t]{2}{*}{ Total } \\
\hline & Normal & Epidural hematoma & Sub dural hematoma & Sub arachnoid hemorrhage & Contusion & \\
\hline \multicolumn{7}{|l|}{ LOC } \\
\hline +ve & 40 & 6 & 22 & 5 & 26 & 99 \\
\hline -ve & 199 & 5 & 3 & 5 & 6 & 218 \\
\hline Total & 239 & 11 & 25 & 10 & 32 & 317 \\
\hline
\end{tabular}


GCS and CT findings were positive in only 33 among them. A total of 38 cases showed moderate GCS and CT findings were positive in almost all cases while all 8 patients with severe GCS showed positive CT findings. Alissa $\mathrm{A}^{19}$ also presented in their study that $32.2 \%$ of patients were below 15 years, $48.2 \%$ were between 16 to 65 years and $19.5 \%$ above 66 years.

Skull fracture was maximally present in the frontal region and epidural hematoma was also found in the same region similar with the findings by Zimmerman and his colleagues who stated that epidural hematoma was most common $(65 \%)$ in temporo-parietal region. ${ }^{22}$ Samudrala $\mathrm{S}$ and Cooper $\mathrm{P}$ stated that epidural hematomas are associated with skull fracture in more than $90 \%$ of patients. ${ }^{23}$ The epidural hematomas are frequently associated with linear fracture according to Phonprasert and his co-workers. ${ }^{24}$ This study was conducted in suspected head injury patients of less than 24 hours duration to evaluate the association of severity of head injury based on GCS score with the findings in head CT scans. Patients of 4 years of age and above were included in this study so that the early GCS scoring system could be used and uniformity is maintained. The early Glasgow Coma Scale is not adapted for smaller children because it lacks brain stem criteria, involves interpretation of motor response and uses verbal response which is of little value before language acquisition. ${ }^{25}$ In the study conducted by Thiruppathy SP and Muthukumar $\mathrm{N}^{26}$, $22 \%$ of patients were children. In this study of 317 patients $80(25.23 \%)$ were below 15 years of age, 221(69.73\%) were between 16 to 65 years and 16(5.04\%) were above 66 years of age.

The neuroradiology of head trauma has undergone dramatic changes since the advent of computed tomography, which has helped significantly to modify the management of head trauma. Head injury patients who sustain sub-lethal intracranial damage tend to recover unless certain secondary effects, like cerebral herniation, traumatic ischemia, infarction, diffuse cerebral edema and hypoxic injury, set in that worsen prognosis. ${ }^{27,28}$ Radiographic evaluation of patients with head injury is one of the initial steps in management of head injury in emergency. Skull $\mathrm{X}$-Rays have a very limited role in head injury particularly in minor head injury. ${ }^{29} \mathrm{CT}$ scan is now the primary modality for evaluation of patients with head injury. ${ }^{30,31}$

\section{CONCLUSION}

The most common cause of head injury was fall and it was more common in children and old people, with the RTA being more common in adults and adolescents. $\mathrm{CT}$ is an integral and important part of management of patients with acute head injury. The presence of vomiting, loss of consciousness and lower GCS scores in a patient with acute head injury can be used as a guideline for ordering CT scans, so that the patient who are in utmost need for undergoing CT can be prioritized, thereby decreasing the financial load to the patient and the load to the CT scan unit.

\section{REFERENCES}

1. Anderson T, Heitger $M$ and Macleod $A D$. Concussion and mild head injury. Practical Neurology 2006; 6(6):342-357.

2. McCaffrey RJ. The practice of forensic neuropsychology: Meeting challenges in the courtroom. Springer Science \& Business Media; 1997.

3. Oslon AD. Head Injury: Practice Essentials, Background, Pathophysiology. Sep 29 2016. http://emedicine.medscape. com/article/1163653-overview.

4. Youmans J. Neurological Society, $5^{\text {th }}$ Edition. Philadelphia: WB Saunders, 2004:5019-5273.

5. Haaga JR, Dogra VS, Forsting M, Gilkeson RC, Kwon H and Sundaram M. CT and MRI of the whole body. Mosby; 2009:317-350.

6. Frankowski RF, Annegers JF and Whitman S. Epidemiological and descriptive studies. Part 1: The descriptive epidemiology of head trauma in the United States. Central nervous system trauma status report. 1985:33-43.

7. Hukkelhoven CW, Stegerberg CW, Rampen AJ, Farace E, Habbema JD and Marshall LF. Patient age and outcome following severe traumatic brain injury: An analysis of 5600 patients. J. Neurosurg 2003; 99: 666-673.

8. Zimmerman RA, Bilaniuk LT, Gennarelli T, Bruce D, Dolinskas C and Uzzell B. Cranial computed tomography in diagnosis and management of acute head trauma. American Journal of Roentgenology 1978;131(1):27-34.

9. Gururaj G. Epidemiology of traumatic brain injuries: Indian scenario. Neurological research 2002;24(1):24-28.

10. Clifton GL, Miller ER, Choi SC, Levin HS, McCauley S, Smith KR, et al. Lack of effect of induction of hypothermia after acute brain injury. New England Journal of Medicine 2001; 344(8):556-563.

11. Poudel-Tandukar K, Nakahara S, Poudel KC, Ichikawa M and Wakai S. Traffic fatalities in Nepal. JAMA 2004;291(21):2542.

12. Hukkelhoven CW, Steyerberg EW, Rampen AJ, Farace E, Habbema JD, Marshall LF, et al. Patient age and outcome following severe traumatic brain injury: An analysis of 5600 patients. Journal of neurosurgery 2003;99(4):666-673.

13. Ainsworth RC. Head Trauma: Background, Epidemiology, Etiology. Jan 09, 2015. http://emedicine.medscape.com/ article/433855-overview.

14. Dacey Jr RG, Alves WM, Rimel RW, Winn HR and Jane JA. Neurosurgical complications after apparently minor head injury: Assessment of risk in a series of 610 patients. Journal of neurosurgery 1986; 65(2):203-210.

15. Singh M, Vaishya S, Gupta S and Mehta VS. Economics of head injuries. Neurology India 2006; 54(1):78.

16. Sutton D, Stevens J and Miszkiel K. Intracranial Lesions (2). Textbook of Radiology and Imaging. $7^{\text {th }}$ ed. London: Churchill Livingstone, 2003:1778-1782.

17. Ingebrigtsen T, Mortensen $\mathrm{K}$ and Romner $\mathrm{B}$. The epidemiology of hospital-referred head injury in northern Norway. Neuroepidemiology 1998; 17(3):139-146.

18. Naseri M, Toumasian A and Moghadas A. Correlation of CT scan 
findings with the level of consciousness in acute head trauma. Iranian Journal of Radiology 2005; 2(3-4): 125-129.

19. Alissa A. Radiological findings in patients who attended the emergency department with head injury: Emergency department, King Hussein Medical Center, Jordan. Middle East Journal of Emergency Medicine 2003; 3(5):b20.

20. Stiell IG, Wells GA, Vandemheen K, Clement C, Lesiuk H, Laupacis A, et al. The Canadian CT Head Rule for patients with minor head injury. The Lancet 2001; 357(9266):1391-1396.

21. Meerhoff SR, De Kruijk JR, Rutten J, Leffers P and Twijnstra A. Incidence of traumatic head or brain injuries in catchment area of Academic Hospital Maastricht in 1997. Nederlands Tijdschrift Voor Geneeskunde 2000; 144(40):1915-1918.

22. Zimmerman RA, Bilaniuk LT, Gennarelli T, Bruce D, Dolinskas $C$ and Uzzell B. Cranial computed tomography in diagnosis and management of acute head trauma. American Journal of Roentgenology 1978; 131(1):27-34.

23. Samudrala $S$ and Cooper P. Traumatic intracranial hematomas. Neurosurgery, Newyork: McGraw Hill 1997:2797-2807.
24. Phonprasert C, Suwanwela $C$, Hongsaprabhas $C$, Prichayudh $P$ and O'charoen S. Extradural hematoma: Analysis of 138 cases. Journal of Trauma and Acute Care Surgery 1980; 20(8):679-683.

25. Oriot D. Assessment of the deepness of coma in children. Evolution of clinical thoughts. Presse Med1994; 23(8):360-361.

26. Thiruppathy SP and Muthukumar N. Mild head injury: Revisited. Acta neurochirurgica. 2004; 146(10):1075-1083.

27. Vitaz TW, Jenks J, Raque GH and Shields CB. Outcome following moderate traumatic brain injury. Surg Neurol 2003; 60:285-291.

28. Osborn AG. Secondary effects of intracranial trauma. Neuro-surg Clin N Amer 1991; 1:461-474.

29. Pitts LH. The role of neuroimaging in minor head injury. Annals of emergency medicine 1991; 20(12):1387-1388.

30. Johnson $\mathrm{MH}$ and Lee $\mathrm{SH}$. Computed tomography of acute cerebral trauma. Radiologic clinics of North America 1992; 30(2):325-352.

31. Brisman $\mathrm{MH}$ and Comins MB. Radiology evaluation in patients with head injury. Mt Sinat J 1997; 64:226-332.

\section{Authors Contribution:}

SM - Concept and design of the study, reviewed the literature, manuscript preparation and critical revision of the manuscript; SC - Concept, Sdata collection, reviewed the literature and preparation of first draft of the manuscript; NA - Literature search and interpretation and critical revision of the manuscript;

PS - Concept of the study, literature search and critical revision of the manuscript.

Source of Support: Nil, Conflict of Interest: The authors declare that they have no conflict of interest. 